\title{
Sherlock Holmes on Screen: the Aesthetics and Politics of Adapting the "Great Detective" in a Hyper-mediatised Age
}

\author{
Sameer Chopra \\ Assistant Professor, Gargi College, University of Delhi. Email: sam1565@gmail.com
}

Received May 25, 2017; Revised July 15, 2017; Accepted July 17, 2017; Published August 09, 2017.

\begin{abstract}
This paper offers a sustained critical analysis of two contemporary adaptations of the immensely popular short-stories by Arthur Conan Doyle that established the fame of Sherlock Holmes, an iconic fictional figure of late nineteenth century British culture: the Granada Television Series, The Adventures of Sherlock Holmes (1984-85) and the 2011 film, Sherlock Holmes: A Game of Shadows (dir. Guy Ritchie). In the main, I argue that while the former subscribes to a cult of fidelity and authenticity, representing the Holmes figure in an alluring yet thoroughly conventional, even stereotypical fashion, the latter not only seeks to fundamentally transform the way the master-detective is portrayed on screen (including a queering of his relationship with his loyal assistant, Dr. John Watson) but also open up the form and structure of the source-texts for textual and ideological reinterpretation. At the same time, the paper also proposes to examine, as indicated in the title, the aesthetics and politics of adaptation as they become manifest in these two texts: why exactly do some representations fetishize faithfulness to original texts as a discursive benchmark whereas others, intentionally or otherwise, are able to irrevocably alter and expand the creative, imaginative and political scope of translating prior materials to the visual media?
\end{abstract}

Keywords: Sherlock Holmes, adaptation, fidelity, popular culture, cinema and television studies, queer readings

In the history of theory and praxis of televisual and cinematic adaptations based on literature, "borrowing" is frequently considered the predominant mode. Here, the creator/director seeks to utilize the content and form of an earlier, usually well-known literary text, hoping to replicate its success and prestige in a different medium. It is assumed that the primary task of adaptation is the reproduction of something "essential" about the source-text. Fidelity to the "spirit" of the original - its authentic essence - thus becomes an aesthetic norm. The oft-rehearsed contention that adaptations are "unfaithful" to or "distort" the creative designs of the authors of the literary materials on which they are based gives expression to what film-theorist Robert Stam (2005) calls an "elegiac discourse of loss," one that takes the axiomatic superiority of literature to visual media for granted (p. 3). The overwhelming currency of the discourse of "fidelity" should not, however, lead us to endorse it uncritically. Recent media-scholars have questioned its essentialist basis, especially in relation to the assumption that the source-text somehow contains a distilled, immutable core of meaning, supposedly emanating from authorial intention, which can be represented verbatim on screen. ${ }^{1}$ How exactly, one might ask, are these intentions to be inferred? The author, particularly from a post-structuralist standpoint, is not so much a uniquely gifted individual, an active shaper of meaning, as a discursive construct, a function that serves to circumscribe a free-flow of signification necessarily embedded in all texts (Foucault, 1979, pp. 141160). Screen adaptations can, in fact, transform, extend, and subvert the source-text in ways that (C) AesthetixMS 2016. This Open Access article is published under a Creative Commons Attribution Non-Commercial 4.0 International License (http://creativecommons.org/licenses/by-nc/4.0/), which permits non-commercial re-use, distribution, and reproduction in any medium, provided the original work is properly cited. For citation use the DOI. For commercial re-use, please contact editor@rupkatha.com. 
can irrevocably nuance the viewers' perception of the adapted materials. In view of such an understanding, my paper attempts to offer a detailed analysis of two adaptations based on the iconic figure of late nineteenth-century British popular culture, Sherlock Holmes - the Jeremy Brett starrer Granada Television Series, The Adventures of Sherlock Holmes (1984-85) and the less doctrinaire 2011 film, Sherlock Holmes: A Game of Shadows (dir. Guy Ritchie) - to argue that when considered comparatively, the latter not only destabilizes the power of the discourse of fidelity outlined above but also the spectators' most cherished, gendered expectations undergirding the myth of the "Great Detective." In the process, the film shifts the vocabulary of adaptation from, to use Lawrence Venuti's terms, the "communicative" to the "interrogative," consistently demystifying the ideological underpinnings of a compulsive infatuation with fidelity and the politics of adapting canonical texts in culturally-sanctioned ways (2012, p. 102).

In the mid-eighties British production, The Adventures of Sherlock Holmes "unquestionably the most important series of Doyle adaptations yet produced for television" (Barnes, 2011, p. 23) - "fidelity" to the short stories authored by Arthur Conan Doyle that became the genesis of the cult of Holmes is manifest in the obsessive replication of the Victorian illustrator Sidney Paget's sketches that first accompanied the serialized texts in The Strand Magazine. In the first episode of the series, "A Scandal in Bohemia," for instance, viewers find Holmes huddled up in a chair by the fireside, knees drawn close to his chest, in an exact recreation of the corresponding illustration by Paget. Such punctiliousness also entailed "issu[ing] a 77-page dossier of facts [culled from the stories]" to the cast and crew, "ranging from a list of Holmes' pipes to an inventory of articles found inside [his famed residence on Baker Street, London] 221 B" (Barnes, 2011, p. 26). Meanwhile, Jeremy Brett, the actor who shot to tremendous critical acclaim for playing the eponymous part, harboured a nearly fanatical zeal to preserve the "quintessence" of Doyle's protagonist, once remarking: "some actors are becomersthey try to become their characters. When it works, the actor is like a sponge, squeezing himself dry to remove his own personality, to absorb the character's like a liquid" (qtd. in Manners, 2001, p. 217). He remains firmly entrenched in popular consciousness as the definitive rendition of Holmes for he appropriated, to brilliant effect, the slightest of visual cues that one almost intuitively associates with the master-sleuth: the deerstalker, the Meerschaum pipe, the tweed overcoat, the magnifying glass and so on. With a tall stature, deep baritone and measured diction, Brett became a suave, authoritative, masculine Holmes, a veritable epitome of refined "English" gentlemanliness. His overpowering, virile screen presence is magnified, throughout the series, through low-angle, ${ }^{2}$ close-up, fully lit shots that enable the viewer to get a conspicuous sense of the organic, unbroken fullness of his body. Deliberately controlled camera movement accentuates the effect of sturdy confidence and calm rationality, as a repertoire of expressions and gestures is deployed to achieve a "realistic" portrayal of the infallible detective. The widely recognized leitmotif of Holmes as a breathtakingly analytical and reclusive individual, shrouded in an aura of inscrutability and eccentricity, is given embodiment on screen in the most infinitesimal particularity.

This ostentatiously cultivated attempt at "faithfulness" is linked to a reactionary impulse to resuscitate a resplendent, museumized past for contemporary audiences. Each episode of the series begins with long shots ${ }^{3}$ of the exquisitely designed Baker Street exterior, saturated with traditional signifiers that evoke the antiquated charm and elegance of Edwardian London: the gas lamps, fog-bound streets, languidly moving gentry and hansom cabs. The camera encourages the audience to relish the splendour of the sets, repeatedly panning across the frame to provide them a delectable spectacle of stately and symmetrical buildings, a laidback, patrician way of life and a highly circumscribed movement of people on the street. The scene does seem bustling with 
activity at first glance but a closer scrutiny reveals that the possibility of its myriad inhabitants coming into contact with each other in random, unpredictable ways has been safely nullified. As a soft, lilting background score fades to indicate the end of the opening credits, the frame turns sepia-tinted, underscoring the irreversible distance engulfing the two implied temporal settings: the past, captured in sensual, wistful pictorial compositions, and the vacuous present, inhabited by a viewer seeking nostalgic refuge in the pleasures of a bygone era wherein current ideological fractures and dispersions are presumed not to have existed. The replica of $221 \mathrm{~B}$, Baker Street, similarly mobilizes visual signifiers - mid-distance shots ${ }^{4}$ of Holmes and his loyal sidekick, Dr. John Watson (David Burke), are carefully orchestrated to highlight the furniture (the mahogany table and bookshelf), the objects, (leather-bound books, decanters, candles, paintings, gilded mirrors, decorated curtains, expensive cutlery, lampshades) and the interiors (the study, the fireplace, the intricately plastered walls and doors) - that make the viewer succumb to the seductive allure of an orderly, decorous "English" past. Evidently, the "past" represented thus is not merely sealed off from the present - "separate from the viewer . . . something over and done with, complete, achieved” (Higson, 1993, p. 117) - but also class-exclusive: the privilege of private property, afforded exclusively to the quasi-aristocratic central characters of Doyle's stories, is rendered aspirational for the viewer as an essentially elite culture gets curiously reconfigured as "national" heritage. The genteel spaces of $221 \mathrm{~B}$, as also the spectacular representation of the manor-house as a discursive site ("Stock Moran" in "The Speckled Band," for instance), sustain the warped, provincial nature of a hierarchically arranged universe; by repeatedly drawing the audiences into admiring the beauty of these properties, the Adventures perpetuates a classist, status-quoist worldview associated with the English upper classes, offering gratifying images of continuity and stability in order to mollify the effects of cultural destabilization and fragmentation ensuing from a more malleable, socially mobile present.

Fidelity, therefore, is not politically innocent. In a significant study, cultural historian John Hill (1999) studies the dynamics of visual representation in the Britain of the 1980s to contend that a potent "Thatcherite" project exerted its influence over all aspects of the country's social life during this period, including the arts. A Conservative government, led by Margaret Thatcher, assumed office in 1979, and sought to enforce a right-leaning political agenda that encapsulated not only economic protectionism and increasing deregulation of the private sector but also a concerted effort to refurbish "organic conservative themes of tradition, family and nation, respectability, patriarchalism and order" (p. 8). Understandably, then, we witness in the television of the day - a medium considered particularly valuable for its didactic potential, "educating and informing" mass-audiences about "national" culture and heritage especially through scrupulous adaptations of "great" nineteenth century texts - a renewed emphasis on the gentlemanly hero, a paragon of a robust, recuperative masculinity, as well as linear, goal-oriented plotlines, partly as a reaction to the breakdown of traditional models of British filmmaking that occurred during the "radical" sixties (Cardwell, 2012, pp. 168-178). The structure of the Adventures, containing thirteen one-hour episodes, is drawn from that of the stories themselves, where all events ultimately culminate in neat, self-congratulatory denouements reinforcing a comforting vision of social order. The reader is always, already aware, this being part of the texts' widespread appeal, that the gentlemanly amateur, imbued with the nonchalant superiority of "Englishness," will eventually restore things as they are. The visual aesthetic of the Adventures reifies this drive toward closure: as Venuti contends in his more general critique of popular reading and viewing strategies, the series seeks to erase "the boundary between art and life through a vicarious participation in the object [of representation], a sympathetic identification with characters as real people which often leads to the inference of moralistic lessons for conduct" (2012, p. 99). At the end of "The Speckled 
Band," for instance, Holmes preaches that "violence does, in truth, recoil upon the violent, and the schemer falls into the pit which he digs for another" (pp. 576-577). The formal and thematic features of the serialized episodes, in extension of the source-texts on which they are modelled, seek to passively immerse the viewer into a naturalistic presentation of plot and character, inadvertently belying the commonsensical notion that the camera is an impartial instrument that grasps "reality" as it is: "what the camera in fact registers," French critics Jean-Louis Comolli and Jean Narboni (1990) remind us, "is a vague, unformulated, un-theorised, unthought-out world of dominant ideology" (p. 6o). The viewer, unable to engage critically with the content on screen, acquiesces to the packaging of the "real" in such a way.

Adaptation, however, need not necessarily be premised on the oppressive straightjacket of fidelity; in re-contextualizing source materials, it can instead alter their significance in fundamental and far-reaching ways, so as to permanently query the logo-centric belief in a single, authoritative meaning that can be safely attributed to a particular text. Recent adapters of Doyle's stories have, for instance, attempted to rupture the artistic and cultural consensus on the subject of the portrayal of the Holmes figure on screen. For Mark Gatiss and Steven Moffat, the creators of the multiple award-winning television series, Sherlock (2010, Season 1), Sherlock Holmes has become so much a "relic," caught in the "trappings- the hansom cabs, the fog, Jack the Ripper will creep in" that a modern rendition of the legendary character seems an undesirable proposition to many (qtd. in Barnes, 2011, p. 168). The staid, conventional representation of Holmes that is routinely rehashed in costume dramas has, in this view, ossified the detective's image in the past, inhibiting newer and more creative ways of interpreting him. In their quest to be recognized as the "definitive" Holmes, numerous actors, from Basil Rathbone and Peter Cushing in the fifties and sixties to Ian Richardson and Jeremy Brett in the seventies and eighties, followed a timehonoured tradition of playing the part, subtly inflecting their performances in peculiar ways, yet remaining perennially wary of disturbing the established prototype. The developers of $A$ Game of Shadows, the particular film-adaptation that I will subsequently examine at greater length initially slammed in the press for being too inauthentic and bastardized - sought to, first and foremost, subvert and falsify this paradigm. Lionel Wigram, former Warner Bros. executive who originated the project, opines:

I'd always felt when I read the original stories that somehow the images that I had in my head of Sherlock Holmes were different than anything I'd seen in a movie. To me, he was much more a Bohemian character . . . a much more modern character . . . Much [as] I love the TV and Masterpiece Theater stuff, the Jeremy Brett stuff, it felt like there was a lot more to be done ... He's a man of action and I felt a very modern character that . . . [the audiences] of today could relate to, both as a misfit and a man who goes his own way (qtd. in Douglas, 2009, para. 12).

Mindful of the inherently contingent and mutable nature of all representation, the film can be seen to defiantly de-essentialize and redefine Holmes for a popular audience accustomed to engaging with him through a thoroughly platitudinous, unimaginative lens.

The outcome is, indeed, inescapably clear. Robert Downey Jr.'s unkempt, debauched, action hero persona breaches the mannered "Englishness" of Jeremy Brett's Holmes. His face remains unshaven, his hair disheveled and clothes scruffy; he also wears a bruised-eye for most of the narrative time. Downey Jr. brings a delightful, Chaplinesque streak to the character, demystifying the Holmes figure by making it a source of comic effervescence. When Downey Jr.'s Holmes realizes, for instance, that one leg of the cross-Europe pursuit of his arch-antagonist, James Moriarty (Jared Harris), will involve riding on a horseback, he quips: "They are dangerous at both 
ends and crafty in the middle. Why would I want anything with a mind of its own bobbing about between my legs?" His bohemianism and decadence, hinted at only subtly in the stories, assume exaggerated proportions here, convincing Dr. Watson (Jude Law) that his mentor-friend, who he notices knowingly consume formaldehyde in place of alcohol, is "manic," even "verging on the psychotic." Other characters in the narrative are not too pleased with Holmes' antics either: as she brings rats on a tray to a room that resembles a mini-jungle, with dense foliage and exotic birds, an alarmed Mrs. Hudson (Geraldine James) urges Watson to take Holmes to a sanatorium because he "rarely sleeps" and lives on a "a diet of coffee, tobacco and cocoa leaves." Unaware that she has been intentionally and strategically hurled out of a moving-train by Holmes into a waterbody below, Watson's newly-wed, Mary (Kelly Reilly), feels hardly reassured by Mycroft's (Stephen Fry) invocation of allegiance to his more famous younger brother: "Over here madam . . . I am the other Holmes," he announces, arriving just in time on a boat to prevent her from drowning. "You mean there is (sic) two of you, oh how marvellous!" she responds sardonically. The film, thus, demystifies the Holmes figure by immersing it into what Russian literary-theorist Mikhail Bakhtin (1981) terms the "creative culture of laughter" (p. 20). Laughter, he notes:

has the remarkable quality of making an object come up close, of drawing it into the zone of crude contact, where one can finger it familiarly from all sides . . . doubt it, . . . dismember it, lay it bare and expose it, examine it freely and experiment with it, . . thus clearing the ground for an absolutely free investigation of it (p. 23).

The inexhaustible, carnivalesque vitality of Downey Jr.'s Holmes undermines the reverential aura and high seriousness that often envelop the venerable detective. Charming in his own way, the "quintessential" Holmes is nonetheless little more than a conglomeration of preconceived cultural expectations, which limit his individuation and reduce him to an insipid formula that is sometimes creatively played around with, but never radically questioned. In contrast, Ritchie's Holmes becomes a site where all fixed identities or essences are contested to foreground their constructedness and provisionality.

While the film is replete with the over-corporeality of Holmes as a martial arts aficionado - emphasizing his pugilistic expertise in heavily-stylized action sequences and overlaying his peerless powers of deduction with an almost James Bond-like swagger - it also queers the male body in such a way that it becomes the site of the deconstruction and reevaluation of heteronormative scripts of gender and sexuality. Ritchie makes a bold departure from the conventional representation of Holmes as a reclusive, unaffected, "calculating machine" (The Sign of Four, p. 105) by suggesting that the detective desires Watson erotically and emotionally. Running parallel to the detective plot is the subtext of Holmes' furtive efforts to sabotage Watson's engagement with Mary. When the matter is first broached, an effete, timorous Holmes tells his befuddled assistant, "your vitality is being drained from you" and only a few scenes later, "marriage is the end of everything." When Watson and Mary seal their wedding union with a kiss, Holmes, in a telling gesture, grimly looks the other way. In a hilarious sequence that follows, a fully cross-dressed Holmes breaks into the train compartment of the honeymoon-bound couple, flings the lady off the train, (avowedly to save her from Moriarty's bullets, but the audience knows Holmes' dislike for her all too well not to connect it with the homoerotic subtext) and tells a horrified Watson: "Lie down with me .. . I insist." The two, forced by a machine gun, cuddle in a sexually suggestive position on the compartment floor. At a peace summit in Switzerland later, they even waltz during a formal ball, Watson bashfully exclaiming to his visibly beaming partner, "I thought you'd never ask!" If heterosexuality is often considered indispensable to being properly and adequately "male," the film manages to undo and relativize such a seemingly unassailable, 
monolithic conceptualization of masculinity, re-examining its problematic status so that it becomes, from an unperturbed given, to a fractured, polyvalent, internally fraught category.

This results in an opposing interpretation of the source-texts that does not resonate well with the audiences' desire to reduce the attachment between the two male leads as merely an instance of deep "friendship." At one point in the narrative, Holmes chides his friend - "That's where we differ. Unlike you, I repress nothing" - suggesting that the doctor seems to be in denial about his love for Holmes, who embraces it all too readily. In characterizing a canonical figure of popular culture as potentially queer, Ritchie challenges the "homosocial/homosexual" as a stable binary opposition, approximating instead the "unbrokenness of a continuum between homosocial and homosexual- a continuum whose visibility, for men, in our society, is radically disrupted" (Sedgwick, 1985, p. 1). Complaints by the Doyle Estate as well as many fans and critics that Ritchie introduced "inaccuracies" in Holmes' character are often motivated by a retrogressive response to the film's critique of the normative "maleness," compulsory heterosexuality being its fundamental precondition. Andrea Plunket, who controls the U.S. copyrights for Doyle's works, actually went to the extent of threatening the producers of Sherlock Holmes (2009, dir. Guy Ritchie), the prequel to $A$ Game of Shadows, that she would withdraw permission for any more sequels if Ritchie decided to further explore romantic undercurrents in the Holmes-Watson relationship. "I am not hostile to homosexuals," she said, "but I am to anyone who is not true to the spirit of the books" (qtd. in Lee, 2010, para. 6). It becomes clear from her submission how the film generates a palpable sense of unease and anxiety among those preoccupied with the cultural reproduction of white, heteronormative masculinity through "authentic" adaptations of the Holmes figure. By establishing a fluid continuum between Holmes' physicality as an action hero, his investigative genius and his comically degenerate "effeminacy," - Downey Jr.'s body language deliberately blurs the boundaries that demarcate "men" from "women" - the cinematic text unleashes a profound crisis at the heart of the very notion of a stable socio-sexual identity, foregrounding its radically decentred, splintered and pluralistic nature. One can better appreciate this divergent, subversive strain in the film by employing Roland Barthes' concept of "third meaning," one that does not carry a sustained, stable semantic charge in the film, is resistant to easy assimilation to the "main" plot and to that extent "indifferent to the story and to the obvious meaning" (1977, p. 61). Precisely for that reason, however, it is "the epitome of a counternarrative" (p. 63). Disregarding attempts to contain and foreclose an uninhibited proliferation of homoeroticism on screen, A Game of Shadows revels in playfully undercutting the authority of "faithful" adaptations with their insistence on conserving a prescriptive heterosexist matrix that delegitimizes potential flows of desire in unforeseeable directions and embodiments of gender that deviate from rigid, binaristic presentations of masculinity and femininity.

This "denaturalizing" of received meanings and identities is carried out not only in the thematic content of A Game of Shadows but also in its formal and structural features, the two being inextricably linked. As it becomes clear to any careful reader of Doyle's stories, the film cheerfully cannibalizes and conflates elements from several of his adventures, bypassing the customary mode of adapting a particular story as a full episode/film, with a strictly delineated sense of beginning, middle and end. Symptomatic of "postmodern" tactics of "quotation" and "juxtaposition," 5 several characters of the Holmes canon who never appear together in a single story (Irene Adler from "A Scandal in Bohemia," Sebastian Moran from "The Empty House," Mycroft from "The Bruce- Partington Plans," Inspector Lestrade from "The Boscombe Valley Mystery" and Moriarty from "The Final Problem") are plucked out of their textual fixity and made to co-exist not only with each other but also those the filmmakers have invented, such as the gypsy fortune-teller, Simza Heron (Noomi Rapace), and Dr. Hoffmanstahl (Wolf Kahler). 
Sometimes, their function in the plot is also at considerable variance with the source texts: Irene Adler, for example, is made Moriarty's confederate. Furthermore, the film employs genre "pastiche" to combine elements of classic detective fiction (focused on analytic deduction), the hardboiled mode (the gritty realism of the streets, rampant violence and direct questioning) and the spy-thriller (the "James Bond" template of one man out to save the world from an arms-driven global catastrophe). In this context, the representation of London becomes particularly pertinent: the cityscape in the film is sinister, alienating and overcrowded, rife with possibilities of uncontrolled violence and gangsterism, dispersion and crime. Ritchie's London, unlike the one invoked in The Adventures of Sherlock Holmes, is not even fleetingly based on order and stability; it is expansive and squalid, even dangerous. In the opening sequence of the film, the viewer gets to witness a quotidian marketplace where the poor jostle with each other, following which a highoctane, elaborately cinematographed street-fight breaks out among members of rival groups. The chaotic, smoke-filled bars and taverns of the London underworld disturb the schematic emphasis on insouciant aristocratic spaces such as the country house and the local inn that had hitherto regularly featured as metonymic symbols of a sumptuous lost world of hierarchy, decorum and permanence in a long tradition of dogmatic adaptations of the Holmes canon. An elaborate, highly dramatic use of chiaroscuro, especially in the action sequences, induces an almost Hogarthian foreboding about the unmapped and unchartered topography of the city. Stylistically, the film alternates between realism and self-conscious artifice (staging certain scenes, such as Holmes, Watson and Simza's Quentin Tarantino-style escape from Moriarty's arms factory, with heightened, computer-generated visual effects) and seriousness and comedy. A purposely amplified use of mise-en-scene ${ }^{6}$ - discontinuous, jerky shots; rapid, chaotic camera movement; frequent cuts and an ingenious use of camera angles - demonstrates a subtle refusal to adopt conventional "realistic" tactics of identification, enabling the spectator to establish a critically nuanced relationship with what is displayed on screen.

In conclusion of my argument, I intend to deliberately juxtapose how the two adaptations under consideration interpret Doyle's "The Final Problem" to contend that whereas the last episode of the TV series participates in an unmistakable eulogizing of the supposedly dead Holmes, turning him into a veritable relic, a defender of official law and order, the film keeps open possibilities of creative departure and narrative polyphony even as it moves towards the climax. Taking a cue from the elegiac tone of Doyle's story, the television episode portrays Holmes as a "national" martyr who selflessly endangers his personal safety to rid his fellow citizens of Moriarty. In a letter that he addresses to Watson before encountering his nemesis at the edge of the Reichenbach Falls, reproduced word by word in the Granada version, Holmes writes:

I am pleased to think that I shall be able to free society from any further effects of his [Moriarty's] presence, though I fear that it is at a cost which will give pain to my friends, and especially, my dear Watson, to you. I have already explained to you, however, that ... no possible conclusion to it could be more congenial to me than this ("The Final Problem," p. 844).

This memorialization is made intensely poignant for the television viewer by turning Holmes even more devotedly pro-establishment than he is envisaged by Doyle. In the narrative, the French government felicitates Jeremy Brett's Holmes at the Louvre Museum for recovering the original Mona Lisa from Moriarty and his accomplices. On his part, the detective lovingly and reverentially cherishes the badge of honour bestowed upon him amidst much ceremonial fanfare; any reference to his decadent excesses, otherwise strewn across the series, is surreptitiously 
cleansed from this episode. Quite inexplicably, Granada's Holmes becomes a cultural messiah, eager to facilitate "the greatest criminal trial of the century" ("The Final Problem," p. 833) and clear up, on his own account, forty cases of deceit, treachery and civic-disorder against Moriarty and his internecine web of criminals. The reclusive bohemian of the earlier episodes, "who loves art [of detection] for its own sake" ("The Copper Beeches," p. 634) and does not bother about public morality, cheerfully allowing unimaginative police inspectors to take credit for the cases he has actually solved, is invisibilized, bolstering a rather reductive, moralistic antithesis between the "good" detective and the "bad" criminal. As slow-motion shots of Holmes and Moriarty descending deep into water pervade the screen, a plaintive background score and dim tones of pale yellow lighting take effect. The camera additionally provides extreme close-ups of the objects Holmes was most intimately associated with: the pipe and its case, his shoes, an ornate pistol and the magnifying glass. The setting is apt for David Burke's Watson to solemnly note, simultaneously referencing two different moments in the source-text: "it's with a heavy heart that I take up my pen to write these last words that I shall ever record the singular gifts with my friend Sherlock Holmes was distinguished" ("The Final Problem," p. 830) and "I shall ever regard him as the best and the wisest man whom I ever known" ("The Final Problem," p. 846). In this concluding episode of the Adventures, then, the finality of meaning that is reinstated at the end of each case that Holmes takes up is brought to bear upon the character himself, as he becomes a static, deified representative of the prevailing socio-political regime. By the end of the show, Holmes assumes a fully "finished" quality- his persona ceases to grow and develop for he is made to shoulder the burden of embodying a distant, Edwardian past, one that the viewer is constantly encouraged to yearningly hark back to. A maudlin finale of this nature not only ensures that the audience is locked in a condition of a nostalgic rapture but also that the politics of representation of the series, with its sensuous, immersive pleasures and absorptive powers, is naively taken for granted, even mistaken for "reality" as such. An insistent emphasis on fidelity as a discursive yardstick necessitates the adaptation of source-texts along dominant, unidimensional models of storytelling and a willful preclusion of possibilities of "critique, extrapolation . . . reaccentuation [and] transculturalization" germane to all acts of translating prior literary materials to the visual media (Stam, 2005, p. 45).

Much to the delight of the purists, $A$ Game of Shadows initially seems to sentimentalize its ending in a similar fashion. A shocked Watson sees Holmes and Moriarty plunging into the Reichenbach Falls, as the frame acquires a somber tinge of bluish-grey and leads the viewer to Holmes' memorial service. All along, the last words of Doyle's text - "there, deep down in that dreadful cauldron of swirling water and seething foam, will lie for all time the most dangerous criminal and the foremost champion of the law of their generation" ("The Final Problem," p. 846) - are played on the background score in the deeply moving, sonorous voice of Jude Law's Watson. Inscribed on one of the pillars of the church is Holmes' epitaph: "In Loving Memory of Sherlock Holmes/1854-1891/He Played the Game for the Game's own Sake.” In a seamless change of scene, Watson is found in his study, typing the final lines of his memoir of Holmes, making customary remarks, drawn exactly from Doyle, about the detective's sagacity and perceptiveness, when Mary enters the frame with a parcel and reminds her husband of their long-deferred honeymoon. The similarities with the source-text and the Granada rendition of it cease here: the spectre of the film undermining its own dissident aesthetic that it had thus far so vociferously espoused is eschewed as the contents of the parcel (a breathing device of Mycroft's that Holmes had used earlier) provide Watson a teasing hint that Holmes might still be alive. As the physician leaves to find out more about the matter, Holmes, who had been present all along in that very same room, emerges from yet another of his bewildering camouflages. The predictable resolution that the last ten 
minutes of the film had anticipated immediately comes to a naught as the "queerly" dressed, anatomically grotesque and un-shapely Holmes re-infiltrates the splendidly ordered interiors of Watson's residence, and upsets, yet again, his beloved friend's attempts to consummate his marriage. In an act of marvelous symbolism, moreover, he places a question mark right next to the phrase "the end," one that Watson had concluded his written panegyric with. At once, the viewer is irrevocably shaken out of a complacent nostalgia that Holmes' "death" had evoked, forced to confront not only his deviancy, both sexual and otherwise, but also an ever-developing, indefatigable dynamism and charisma of his disposition. The mythos of the aesthetically and ideologically settled, unified Holmes is permanently dispensed away with; the most significant intervention that the film makes, in fact, is the creation of a Holmes that the audience can cheerfully look forward to changing and evolving - his refreshing pliability - unlike the frozen archetype or, in Ritchie's words, the "posh, homogenized individual, . . . [t] he quintessential lofty toff" of previous adaptations (qtd. in Barnes, 2011, pp. 194-195). It "queers," both literally and metaphorically, a figure that is typically fetishized in popular culture as an exemplar of idealized machismo, rational order and a panoptic vision of power and control.

Salman Rushdie (1991) decries the "refurbishment of the Empire’s tarnished image" (p. 91) and "recrudescence of imperialist ideology" (92) in the British heritage films/television programmes of the eighties era: " $[t]$ he continuing decline, the growing poverty, and the meanness of spirit of much of Thatcherite Britain encourages many Britons to turn their eyes nostalgically to the lost hour of their precedence" (pp. 91-92). This, he adds, was simultaneous with the "rise of conservative ideologies in modern Britain" (p. 92). The aesthetics and politics of representation of Granada's Adventures are unarguably implicated in this cultural obsession with looking back. With a disproportionate investment in "fidelity" and "authenticity," discernible, among other things, in a commonplace, stereotypical portrayal of the Holmes figure, the series is resistant to the liberating potentialities inherent in the process of visual adaptation. The audiences are prompted to unthinkingly accept its meanings as predetermined and already-achieved and desist from revisiting the apparently immutable, conclusive nature of its form and content. A Game of Shadows, on the other hand, occupies a far more ambiguous position vis-à-vis its source-texts: while set in Victorian England, thus circumventing radical de-contextualization, it introduces, through a strategic use of humour, irony and pastiche, a spirit of interrogation and critique manifest both in the reconfiguration of the Holmes figure -which becomes permeated with elements of self-deprecating comedy and a much-needed open-endedness - and a postmodernist revitalization of form that queries the organic conclusiveness of the television series. In doing so, it effectively transforms, to borrow Barthes' terms again, the "readerly" texts of Doyle (and their "faithful" adaptations) - predicated on linear plot-lines and traditional signifying practices - into "writerly" ones, where stable meanings, or metanarratives, are replaced by a profound disregard for narrative closure (Allen, 2003, 88-92). This, in turn, recasts the role of the spectators: from being passive consumers of tractable, premeditated significations, they become active producers of new, radical ones. Adaptation is hence accorded an entirely novel, unconventional significance: heretofore wholly subservient to the touchstone of fidelity - and mired in classist, sexist and homophobic political imperatives - it appropriates for itself a far more complex, variegated valence, opening up the "classic" Holmes format to a multitude of alternative, heterodox ways of seeing and being. 


\section{Notes}

${ }^{1}$ For a comprehensive overview of the critical objections to the fidelity discourse, see Leitch, 2012, pp. 104119.

${ }^{2}$ A low-angle shot is a shot from a camera placed below the eye-line, looking up, to enhance the power and fleshiness of the object of representation.

${ }^{3}$ The long shot is used for setting the scene. It usually shows an exterior, e.g. the outside of a building or a landscape.

${ }^{4}$ A mid-distance shot frames the body amidst a visually striking setting. Unlike the long shot, it evens its focus out between the human figure and the backdrop.

${ }^{5}$ For an introductory account of the key terms of post-modern theory, see Wood, 2010, pp. 1-17.

${ }^{6}$ In film studies, mise-en-scene broadly refers to the visual specificities of film production, such as setting, props, costume and lighting, camera movement and framing and so on.

\section{References}

\section{Primary Sources:}

Cox, P. (Producer), \& Hawkesworth, J. (Developer). (1984-1985). The Adventures of Sherlock Holmes [Television Series]. UK: ITV Granada.

Doyle, A C. (1890). The Sign of Four. The Complete Illustrated Sherlock Holmes (97-174). New Delhi: Rupa, 1986.

---. (1891). A Scandal in Bohemia. The Complete Illustrated Sherlock Holmes (429-448). New Delhi: Rupa, 1986.

---. (1892). The Copper Beeches. The Complete Illustrated Sherlock Holmes (634-654). New Delhi: Rupa, 1986.

---. (1892). The Speckled Band. The Complete Illustrated Sherlock Holmes (558-578). New Delhi: Rupa, 1986.

---. (1893). The Final Problem. The Complete Illustrated Sherlock Holmes (830-846). New Delhi: Rupa, 1986.

Wigram, L. (Producer), \& Ritchie, G. (Director). (2011). Sherlock Holmes: A Game of Shadows [Motion Picture]. USA: Warner Bros. Pictures.

\section{Secondary Sources:}

Allen, G. (2003). Roland Barthes (Routledge Critical Thinkers). London: Routledge.

Bakthin, M. (1981). Epic and Novel: Toward a Methodology for the Study of the Novel. In M. Holoquist (Ed.), The Dialogic Imagination: Four Essays (3-40). (C. Emerson and M. Holquist, Trans.). Texas: University of Texas Press.

Barnes, A. (2011). Sherlock Holmes on Screen: The Complete Film and TV History. London: Titan Books.

Barthes, R. (1977). The Third Meaning: Research Notes on Some Eisenstein Skills. Image Music Text (52-68). (S. Heath, Trans.). London: Fontana Press.

Cardwell, S. (2012). Literature on the Small Screen: Television Adaptations. In T. Corrigan (Ed.), Film and Literature: An Introduction and Reader (168-178). London and New York: Routledge. 
Comolli, J L., \& Narboni, J. (1990). Cinema/Ideology/Criticism. In N. Browne (Ed.), Cahiers du Cinéma Volume 3 1969-1972: The Politics of Representation (58-67). London: Routledge.

Douglas, E. (2009, March 5). CS on Location with Sherlock Holmes. Comingsoon. Retrieved from http://www.comingsoon.net/movies/features/53180-cs-on-location-with-sherlock-holmes

Foucault, M. (1979). What is an Author? In J V Harari (Ed.), Textual Strategies: Perspectives in PostStructuralist Criticism (141-160). New York: Cornell University Press.

Higson, A. (1993). Representing the National Past. In L. Friedman (Ed.), Fires were Started: British Cinema and Thatcherism (109-129). Minneapolis: University of Minnesota Press.

Hill, J. (1999). British Cinema in the 1980s: Issues and Themes. Oxford: Clarendon Press.

Lee, A. (2010, January 4). Sherlock Holmes Sequel under Threat Because of Gay Hints. Metro. Retrieved from http://metro.co.uk/2010/o1/o4/guy-ritchies-sherlock-holmes-sequel-under-threat-because-ofgay-hints-11347/

Leitch, T. (2012). Twelve Fallacies in Contemporary Adaptation Theory. In T. Corrigan (Ed.), Film and Literature: An Introduction and Reader (104-122). London and New York: Routledge.

Manners, T. (2001). The Man Who Became Sherlock Holmes: The Tortured Mind of Jeremy Brett. London: Virgin Publishing Ltd.

Rushdie, S. (1991). Outside the Whale. Imaginary Homelands: Essays in Criticism 1981-1991 (87-101). London: Granta Books.

Sedgwick, E K. (1985). Between Men: English Literature and Male Homosocial Desire. New York: Columbia University Press.

Wigram, L. (Producer), \& Ritchie, G. (Director). (2009). Sherlock Holmes [Motion Picture]. USA: Warner Bros. Pictures.

Stam, R. (2005). Introduction: The Theory and Practice of Adaptation. In R. Stam and A. Raengo (Eds.), Literature and Film: A Guide to the Theory and Practice of Film Adaptation (1-52). Oxford: Blackwell.

Venuti, L. (2012). Adaptation, Translation, Critique. In T. Corrigan (Ed.), Film and Literature: An Introduction and Reader (89-103). London and New York: Routledge.

Wood, T. (2010). Beginning Postmodernism. New Delhi: Viva Books.

Sameer Chopra teaches English as Assistant Professor at Gargi College, University of Delhi. He holds an MPhil from the Department of English, University of Delhi, and takes special interest in teaching and researching on postcolonial queer culture (texts as well as contexts), popular cinema and television, and the literary and visual traditions of European Modernism in the early twentieth century. 